стабилизирует транс-конформер А, вероятно, за счет изменения конфигурации молекулярных орбиталей из-за электронных взаимодействий с остовом нанотрубки.

$$
* * *
$$

1. Osamura Y., Schaefer H.F. Internal rotation barrier and transition state for glyoxal // Journal of Chemical Physics. 1981. V. 74. № 8. P. 4576-4580.

2. Кузнецов В.В. Конформационные свойства этана и его аналогов в нано-трубках // Российский химический журнал. 2017. Т. Т. 61. № 1. С.37-47.

3. Laikov D.N., UstynyukYu.A. PRIRODA-04: a quantum-chemical program suite. New possibilities in the study of molecular systems with the application of parallel computing// Russian Chemical Bulletin. 2005. V. 54. № 3. P. 820-826.

\title{
Бочкор С.А., Кузнецов В.В. \\ Ацетилен в фуллерене С60: пример взаимодействие силового поля наноструктуры с тройной углерод-углеродной связью
}

Уфимский государственный нефтяной технический университет Уфимский государственный авиаџионный технический университет

(Россия, Уфа)

doi:10.18411/spc-16-01-2018-08

idsp: 000001:spc-16-01-2018-08

\section{Аннотация}

B рамках расчетного DFTприближения $\mathrm{PBE} / 3 \zeta$ на примере эндокомплекса ацетилена с фуллереном С60, показано, что силовое поле нанообъекта меняет электронные и энергетические характеристики гостевой молекулы, в частности, понижает порядок тройной углерод-углеродной связи и сокращает ее длину.

Ключевые слова: ацетилен, фуллерен, порядок тройной связи, компьютерное моделирование.

\section{Abstract}

In the frame of computational DFT approximation $\mathrm{PBE} / 3 \zeta$ using endocomplex of acetylene with fullerene $\mathrm{C} 60$ as an example it has been shown that the force field of nanoobjectchanges the electronic and structural parameters of guest molecule, in particular, decreases the order of triple carbon-carbon bond and cuts its length.

Keywords: acetylene, fullerene, order of triple bond, computer simulation.

Влияние силового поляфуллеренов на структурные и конформационные характеристики инкапсулированных молекул наглядно демонстрируется примером заметного возрастания барьера внутреннего вращения, а также сокращения длин всех связей молекулыэтана в фуллерене С60[1].В этомотношении представляет значительный интерес исследование эндокомплексов фуллеренов с гостевыми молекулами, содержащими кратные связями. Целью настоящей работы является изучение влияния фуллерена С60 на структурные изменения инкапсулированной

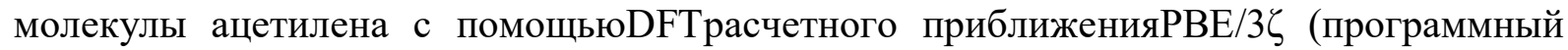
комплекс ПРИРОДА [2]).

Полученные результаты свидетельствуют о заметных различиях в структурных и энергетических характеристиках молекул свободного (рис. 1) и заключенного в полость фуллерена (рис. 2) ацетилена.

Как и в других случаях [1] силовое поле фуллерена «сжимает» инкапсулированную молекулу, приводя к заметному сокращению длин связей. Помимо этого, существенно уменьшается порядок тройной связи по Малликену и значения отрицательных зарядов на атомах углерода. Положительный заряд на водородных атомах, наоборот, возрастает. В результате молекула ацетилена в полости фуллерена 
приобретает результирующий положительный заряд (0.32), хотя в целом система C2H2@C60 остается электрически нейтральной. Данное явление наблюдается для всех ранее исследованных эндокомплексов малых молекул с фуллеренами [1] и нанотрубками [3], свидетельствуя о заметном переносе заряда с гостевой молекулы на остов наноструктуры.

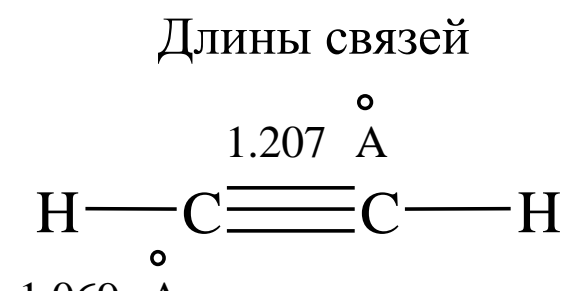

Заряды на атомах и порядки связей

$1.069 \mathrm{~A}$

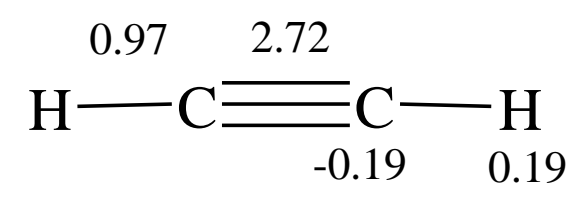

Рис. 1. Параметры свободной молекуль С2H2
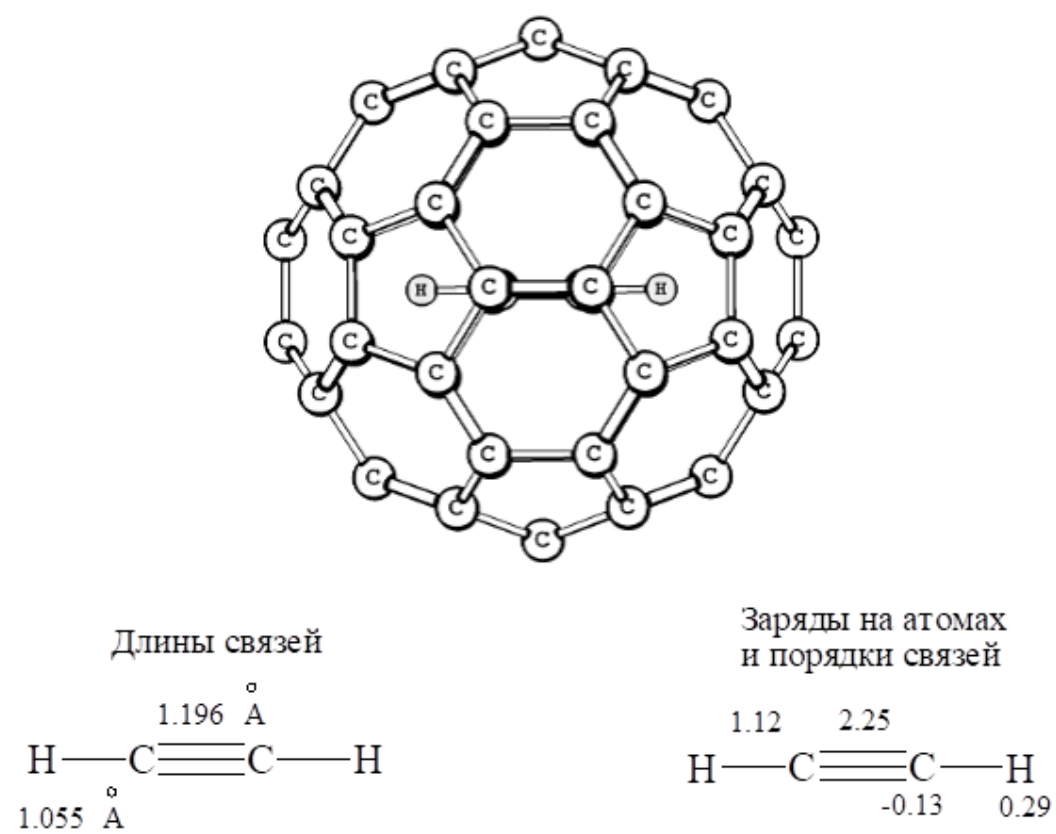

Рис. 2. Параметры молекуль С2Н2в эндокомплексе

Таким образом, молекула ацетилена в модельном фуллерене в результате структурной перестройки приобретает новые свойства, которые можно использовать для осуществления разнообразных химических реакций в полости наноструктуры с целью синтеза новых практически полезных материалов.

$$
* * *
$$

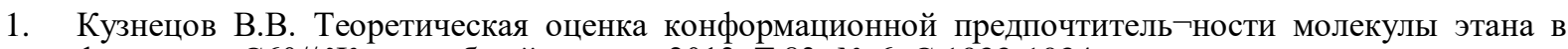
фуллерене С60// Журналобщейхимии - 2013. Т.83. № 6. С.1033-1034.

2. Laikov D.N., UstynyukYu.A. PRIRODA-04: a quantum-chemical program suite. New possibilities in the study of molecular systems with the application of parallel computing// Russian Chemical Bulletin. 2005. V. 54. № 3. P. 820-826.

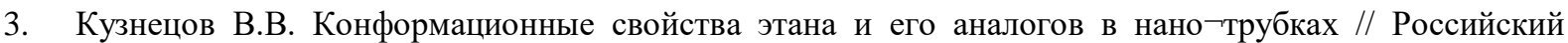
химический журнал. 2017. Т. Т. 61. № 1. С.37-47. 